\title{
Educação física escolar: uma leitura na concepção emergente do desenvolvimento humano
}

\author{
Silvia Christina Madrid Finck*
}

\begin{abstract}
RESUMO
O objetivo principal neste trabalho é focalizar alguns aspectos da Educação Física Escolar utilizando como referencial teórico uma das teorias que tratam do Desenvolvimento Humano, a Teoria Ecológica de Urie Bronfenbrenner, interpretada e discutida pelo Prof ${ }^{\circ}$ Rui Jornada Krebs. Primeiramente evidencia-se alguns questionamentos que permeiam a Educação Física Escolar, os quais fazem parte da realidade que vivencia-se e das preocupações que se têm. Em seguida, aborda-se sobre o Desenvolvimento Humano, sua relação com o comportamento e seus principais princípios numa perspectiva ecológica. Dentre as teorias emergentes que tratam do Desenvolvimento Humano, optou-se pela Teoria Ecológica de Urie Bronfenbrenner para discutir algumas questões que permeiam a Educação Física Escolar. Dessa forma, situa-se a escola enquanto um microssistema, a aula de Educação Física como atividade molar, os diferentes papéis que são vivenciados pelas pessoas, principalmente o aluno, no ambiente da escola, assim como, as estruturas interpessoais que nela são estabelecidas. Algumas considerações são colocadas no término do trabalho não no sentido de concluir, mas de instigar outros questionamentos que envolvem o tema em questão e que possam vir a colaborar para seu enriquecimento.

Palavras-chave: Educação Física escolar, desenvolvimento humano, teoria cológica

\footnotetext{
${ }^{1}$ Professora Assistente na Universidade Estadual de Ponta Grossa/Pr, no Departamento de Métodos e Técnicas de Ensino, na disciplina de Metodologia e Prática de Ensino de Educação Física, do Curso de Licenciatura em Educação Física.

Olhar de professor, Ponta Grossa, 1(1):91-106, out. 1998.
} 


\section{Introdução}

O objetivo principal neste trabalho é focalizar alguns aspectos da Educação Física Escolar utilizando como referencial teórico uma das teorias que tratam do Desenvolvimento Humano, a Teoria Ecológica de Urie Bronfenbrenner, interpretada e discutida pelo Prof ${ }^{0}$ Rui Jornada Krebs.

Alguns questionamentos que permeiam a Educação Física Escolar são evidenciados, os mesmos fazem parte da realidade cotidiana que vivese na escola e caracterizam as preocupações que se têm. De forma breve, são tecidas algumas considerações, segundo Krebs, sobre algumas tendências teóricas sobre o Desenvolvimento Humano, aborda-se também sobre sua relação com o comportamento e seus principais princípios numa perspectiva ecológica.

Dentre as teorias emergentes que tratam do Desenvolvimento Humano, optou-se pela Teoria Ecológica de Urie Bronfenbrenner para a discussão de algumas questões que permeiam a Educação Física Escolar. Dessa forma, situa-se a escola enquanto um microssistema, a aula de Educação Física como atividade molar, os diferentes papéis que são vivenciados pelas pessoas, principalmente o aluno, no ambiente da escola, assim como, as estruturas interpessoais que nela são estabelecidas. Finalmente faz-se algumas considerações as quais não têm um sentido conclusivo, mas sim provocativo na direção de outros questionamentos que envolvem o tema em questão e que possam vir a colaborar para seu enriquecimento.

\section{A educação física na escola: al- guns questionamentos}

As discussões em torno da Educação Física se acirraram a partir da década de 80, de lá para cá pode-se dizer que houve um avanço científico em torno das diversas questões que dela fazem parte, entre elas às que envolvem a Educação Física Escolar. A começar pelo questionamento da terminologia, havendo sugestão de mudança para Educação Motora, não sendo apenas uma questão de denominação, mas de todo um paradigma que a sustenta. Alguns estudiosos da área se posicionam a esse respeito, entre eles DE MARCO que diz:

Não se trata de uma simples mudança conceitual (de educação física para educação motora), porém a discussão aprofundada do termo deve gerar mudanças no nível da consciência profissional e da prática cotidiana, orientando uma clara definição do objetivo de estudo da educação física ou da educação motora, se aceitarmos a substituição acadêmica e legal do termo que define a atual área de conhecimento denominada educação física. ${ }^{2}$

${ }^{2}$ DE MARCO, Ademir. Educação Física ou Educação Motora?. In DE MARCO, Ademir (org.). Pensando a Educação Motora. Campinas, SP: Papirus, 1995, p. 34. 
Outros como FREIRE refere-se à essa questão dizendo:

O termo educação motora por si só não representa mudança substancial no campo de conhecimento de que estamos falando. Porém, em torno dele, uma série de práticas, de rituais, de atitudes pode ser realizada, carregando-o de significados. Entre outras coisas, pode significar a menção de uma dimensão humana que remeta para a dimensão total humana. Podemos, em nossos rituais de tratamento do termo, caracterizálo como um termo que, ao se referir ao homem, refira-se a uma parte que remeta ao todo. Não é um termo comprometido com os dualismos. $^{3}$

Diante desses posicionamentos pode-se verificar que existe necessidade de mudanças que vão desde a terminologia até, e principalmente, de atitude profissional, que envolve o conhecer (competência), o perceber (realidade) e o compromisso (político e social)

É necessário que a nossa tão conhecida Educação Física, preocupada com a execução mecânica do movimento, com a performance e o rendimento, que visualiza o indivíduo de forma fragmentada e reducionista, se despoje disso tudo (de suas "certezas") para trilhar um novo caminho, já iniciado por alguns poucos, mas ainda faltando muito para ser percorrido.

A Educação Física Escolar sempre foi o centro de minhas preocupações profissionais e acadêmicas, especificamente as questões que envolvem o ensino aprendizagem, processo esse complexo e contraditório. Entre as várias questões que envolvem a Educação Física Escolar podese citar: o conhecimento de que ela trata (conteúdos), o que é priorizado e para que estamos ensinando (o que pretendemos/objetivos), a forma como o conhecimento é tematizado e transmitido (metodologia), as relações que são estabelecidas no espaço da aula (professor/aluno; aluno/aluno).

Embora muito já venha sendo discutido, sobre essas questões, pela comunidade científica da Educação Física, as mesmas não atenuam a complexidade e as contradições que a permeiam na escola. A complexidade é caracterizada, principalmente, pelo fato de envolver pessoas diferentes, as quais estabelecem diferentes relações com intensidade e intenções diferentes, que por sua vez assimilam àquilo que lhes é transmitido de forma também diferenciada, tornando tal processo ao mesmo tempo contraditório e extremamente rico.

Essa complexidade, contradição e riqueza, muitas vezes não são consideradas, com isso se perde e corre-se

${ }^{3}$ FREIRE, João Batista. Antes de falar de Educação Motora. In DE MARCO, op.cit., p. 38. 
o risco do não avanço e da estagnação, necessário se faz uma nova postura do professor diante do processo ensino aprendizagem, que tem a ver com suas concepções (valores/história de vida) e competência profissional (conhecimento).

O principal centro no processo ensino aprendizagem é o aluno, um ser em desenvolvimento, nos seus mais diferentes aspectos, que possui características físicas e psicológicas que são interrelacionadas, o mesmo está inserido num meio ambiente, portanto é um ser social, e que na escola (microssistema), um dos ambientes, ele realiza tarefas (atividade molar), que têm (ou deveriam ter?) sempre um significado.

Tendências teóricas do desenvolvimento humano: algumas considerações

Segundo KREBS ${ }^{4}$, as tendências teóricas podem ser assim agrupadas e divididas: tradicionais, contemporâneas e emergentes, as que fazem parte deste último grupo são tidas como sendo àquelas que irão nortear os estudos do Desenvolvimento Humano no próximo milênio. $\mathrm{O}$ referido autor evidencia que o estudo do Desenvolvimento Humano tem sido, ao longo do tempo, explicado pelas mais dife- rentes teorias. Essas diferenças, no entanto, não devem ser interpretadas como se houvesse alguma teoria correta, e que todas as outras, diferentes estariam erradas. O que essas diferenças refletem, na verdade, é que cada teoria busca explicar algum aspecto do desenvolvimento, em relação a algum determinado fenômeno.

Historicamente, essas posições contraditórias remontam à questão da importância dos fatores hereditários sobre os ambientais e vice-versa. A primeira posição foi caracterizada como uma tendência maturacionista no estudo do Desenvolvimento $\mathrm{Hu}-$ mano, e a segunda foi caracterizada como uma tendência ambientalista. Em relação às tendências teóricas do desenvolvimento, foi possível perceber que enquanto as teorias tradicionais tentavam destacar a importância, ou dos fatores internos, ou dos fatores externos, as teorias mais contemporâneas mostram a interação entre esses dois fatores. Também as posições teóricas polarizadas, tipo humanismo versus tecnicismo, deram lugar a interpretações dialéticas que enfatizam a necessidade de mediação das contradições, como condição para o desenvolvimento. Essas posições divergentes dos teoristas do Desenvolvimento Humano tem sido tema de estudo, que tentam analisar e explicar essas diferentes vertentes teóri-

${ }^{4}$ KREBS, Rui Jornada. et al. Desenvolvimento Humano: uma área emergente da ciência do movimento humano. Santa Cruz do Sul, RS: [s.n.], 1996. 
cas. $^{5}$

As tendências teóricas que irão nortear o estudo do Desenvolvimento Humano no próximo milênio, apontam para a necessidade de se entender o Desenvolvimento Humano como um sistema ecológico, em que o ser humano, é, ao mesmo tempo, produto e produtor das condições para o seu desenvolvimento.

\section{Relação entre desenvolvimento e comportamento}

O Desenvolvimento Humano, como área de investigação, busca explicar o processo de mudanças inerentes ao ser humano. Esse processo é um fenômeno de natureza dinâmi$\mathrm{ca}$, onde os fatores internos e externos estão em constante interação. $\mathrm{O}$ desenvolvimento por ser um processo longitudinal irreversível reflete uma fase ascendente, caracterizada por ganhos e aumentos, uma fase mais ou menos estável, caracterizada pela manutenção e equilíbrio dos atributos pessoais, e uma fase de decadência, caracterizada pelas perdas e diminuição das potencialidades humanas.

O comportamento humano foi an- teriormente caracterizado como uma ação, resposta, ou produto, que serve como expressão de todas as capacidades do ser humano. Assim como o desenvolvimento, o comportamento não pode ser fragmentado ou entendido como um somatório de atributos independentes. No entanto, em qualquer expressão humana, podemos observar os atributos que se manifestam de forma mais evidente que os demais, e isso nos permite formular o conceito de domínios do comportamento.

Nas aulas de Educação Física podemos apontar situações ludo-gminoesportivas que embora o comportamento mais evidente que o indivíduo manifeste seja o motor (domínio motor), todos os movimentos por ele realizados têm uma intenção e uma carga emocional (domínio cognitivo e afetivo), além dos seu significado cultural (domínio social). Podemos, portanto, observar a relação dos domínios do Desenvolvimento Humano com as respectivas variáveis de comportamento. KREBS diz:

É muito importante alertar-se que essa subdivisão dos domínios do desenvolvimento é apenas uma estratégia didática para salientar os comportamentos dominantes,

\footnotetext{
${ }^{5}$ Nesse sentido pode-se apontar as seguintes obras: THOMAS, Robert M. (1992). Comparing Theories of Child Development. $3^{\mathrm{a}}$ ed. Belmont: Wadsworth Publishing Company. Tal obra é tida como um dos mais completos estudos sobre teorias do desenvolvimento da criança. KREBS, Rui Jornada (1995). Desenvolvimento Humano: teorias e estudos. Santa Maria, RS: Casa Editorial, 1995. Nesta obra o autor apresenta uma periodização detalhada das teorias do desenvolvimento humano.
} 
e a que processos de mudança desenvolvimentista eles estão associados, pois assim como o desenvolvimento deve ser entendido em sua totalidade, o comportamento não pode, em hipótese alguma, ser tomado como uma ação inerente a um único atributo do desenvolvimento. ${ }^{6}$

As variáveis manifestadas através do comportamento podem ser observadas indicando qual o processo do desenvolvimento se manifesta de forma mais evidente. Por exemplo, numa situação competitiva numa aula de Educação Física, o aluno embora esteja executando movimentos que envolvem coordenação, equilíbrio, etc., e este seja até dominante (domínio motor), o aluno está em situação de interação e oposição com seus colegas, onde ele poderá sentir prazer, frustração, alegria ou raiva (domínio afetivo) assim como vivenciar situações de cooperação, liderança e outras (domínio social) e ainda elaborar estratégias para obter êxito na competição (domínio cognitivo).

Portanto, pode-se dizer que o aluno ao realizar movimentos nas aulas de Educação Física, manifesta comportamentos observáveis de forma interrelacionada, os quais revelam que seu desenvolvimento não se dá apenas no aspecto físico, mas na sua totalidade.

\section{Princípios do desenvolvimento humano}

A sistematização dos princípios do Desenvolvimento Humano depende do suporte teórico utilizado, a orientação teórica aqui é defendida pela abordagem ecológica humana proposta por Bronfenbrenner (KREBS, 1995), e pela abordagem lifespan (ao longo da vida) enfatizada por Hughes e Noppe (1985) e por Rice (1992) ${ }^{7}$.

Dessa forma, os princípios são os seguintes:

$\left.1^{\circ}\right) \mathrm{O}$ desenvolvimento é multidimensional e interdisciplinar. Este princípio estabelece que dimensões de ordem biológica, psicológica e social mantém uma relação de interdependência entre elas, isto é, cada uma possui características específicas (identidade) e, ao mesmo tempo, reflete as características das demais (interdisciplinaridade). Este princípio confere ao desenvolvimento uma característica holística, que contraria a idéia de que o todo seja igual à soma de suas partes.

$\left.2^{\circ}\right) \mathrm{O}$ desenvolvimento reflete continuidade e descontinuidade. Thomas (1992) ${ }^{8}$ aponta a questão do Desenvolvimento Humano ser um processo contínuo ou não como sendo um dos critérios para a análise do

\footnotetext{
${ }^{6}$ Op. cit., p.14.

${ }^{7}$ In KREBS, 1996, op. cit.

${ }^{8}$ Idem
} 
conteúdo de uma teoria de desenvolvimento. Esse autor enfatiza que as teorias não definem apenas as direções das mudanças, mas também se as mesmas ocorrem gradualmente, ou de forma descontínua. Rice (1992) concorda que o desenvolvimento reflete ambos, continuidade e descontinuidade. Para ele, as teorias que tendem a apresentar o desenvolvimento como um processo contínuo, enfatizam a importância das influências ambientais e a aprendizagem social. Por outro lado, os teoristas que defendem o desenvolvimento como um processo descontínuo, subdividindoo em períodos ou estágios característicos, destacam a importância da hereditariedade e da maturação em todos os processos de mudança que caracterizam o desenvolvimento.

$\left.3^{\circ}\right) \mathrm{O}$ desenvolvimento é cumulativo, porém dinâmico. O Desenvolvimento Humano ao ser considerado como um processo ao longo da vida, as transformações, que vão sendo determinadas pelos fatores internos $\mathrm{e}$ externos, tendem a permanecer como características desenvolvimentistas. No entanto, esse processo cumulativo não deve ser entendido como um mero processo de soma de atributos. As características de desenvolvimento que acumulam-se ao longo da vida dependem sempre da inter-relação dinâmica dos atributos internos e externos. Por exemplo, o crescimento de uma criança é determinado por fatores internos (relógio biológico), mas se ele vai se dar em toda sua potencia- lidade depende de fatores externos, como o meio onde ela vive e sua qualidade de vida (alimentação, cuidados com a saúde etc.). Portanto, seu desenvolvimento físico vai depender dessa inter-relação, que por sua vez está relacionado com os outros aspectos, o psicológico e o social, que irão influenciar o desenvolvimento em outras dimensões.

$4^{\circ}$ ) O desenvolvimento reflete tanto a individualidade quanto a universalidade do ser humano. A questão das diferenças individuais pode ser discutida tanto com base nos atributos biológicos quanto nos socioculturais. A hereditariedade dos genitores e as condições ambientais asseguram que cada ser humano seja um indivíduo único, porém, a hereditariedade da espécie assegura a cada indivíduo, características universais da espécie humana.

Os teóricos do Desenvolvimento Humano buscam explicar essa aparente contradição. Eles apontam as características maturacionais como exemplo da universalidade do ser humano, pois independente da raça, da etnia, ou da nacionalidade, o ritmo de maturação parece obedecer a um mesmo relógio biológico.

Esses princípios apontam para a complexidade que é o desenvolvimento do ser humano, caracterizado por variáveis que estão interrelacionadas, fazendo também de cada indivíduo um ser único e inconfundível. Portanto, o professor não pode tratar seus alunos como se todos fos- 
sem iguais, padronizando movimentos não respeitando sua individualidade, expressão e cultura. É importante que o professor de Educação Física na escola visualize cada aluno como um ser único em desenvolvimento.

\section{A teoria da ecologia do desen- volvimento humano, de Bronfenbrenner}

A Teoria Ecológica do Desenvolvimento Humano é tida por KREBS (1995) como uma das teorias projetadas para o próximo milênio, a mesma é proposta por Urie Bronfenbrenner (1979), sendo caracterizada por uma concepção sistêmica da qual fazem parte elementos formadores. KREBS desenvolveu estudos na área da Educação Física utilizando como suporte teórico essa teoria.

A ecologia do Desenvolvimento Humano envolve o estudo científico da acomodação progressiva, mútua, entre um ser humano ativo, em desenvolvimento, e as propriedades mutantes dos ambientes imediatos em que a pessoa em desenvolvimento vive, conforme esse processo é afetado pelas relações entre esses ambientes, e pelos contextos mais amplos em que os ambientes estão inseridos. ${ }^{9}$

Bronfenbrenner (1979) viu a relação dinâmica entre o ser humano em desenvolvimento e suas constantes interações com o contexto ambiental, tal relação é "como uma avenida com duas vias, tanto o contexto influencia a pessoa em desenvolvimento, quanto a pessoa influencia os ambientes aos quais ela está relacionada, desde a dimensão mais imediata até a mais distante." ${ }^{10}$ Ele enfatiza o Desenvolvimento Humano como um conjunto de sistemas aninhados em que a pessoa em desenvolvimento é, ao mesmo tempo, capaz de ser influenciada por esses sistemas, como também determinar mudanças que neles ocorram.

A teoria é composta, sob o aspecto ambiental, por blocos construtores e a maioria são conceitos familiares nas ciências comportamental e social entre eles: atividade molar, díade, papel, ambiente, rede social, instituição, subcultura, cultura. O que é novo é a maneira pela qual essas entidades se relacionam entre si e ao curso do desenvolvimento. ${ }^{11}$ Em relação ao mundo externo o que é apresentado é uma teoria das interconexões ambientais e seu impacto sobre as forças que afetam o crescimento psicológico.

Alguns principais pressupostos

${ }^{9}$ BRONFENBRENNER, Urie. A Ecologia do Desenvolvimento Humano: experimentos naturais e planejados. Trad. Maria Adriana Veríssimo Veronese. Porto Alegre, RS: Artes Médicas, 1996, p. 18. ${ }^{10}$ KREBS, Rui Jornada (org.). Desenvolvimento Humano: teorias e estudos. Santa Maria, RS: Casa Editorial, 1995, p. 103.

${ }^{11}$ Op. cit. 
dão suporte à elaboração da estrutura sistêmica da teoria, o primeiro conjunto dos mesmos são identificados como os elementos do ambiente, a partir dessa identificação é possível analisarem-se diferentes ambientes classificados como microssistemas e, ainda, as forças que afetam o Desenvolvimento Humano a nível de mesossistema, exossistema, e macrossistema. O meio ambiente ecológico é concebido topologicamente como uma organização de encaixe dessas estruturas concêntricas, cada uma contida na seguinte, seriam os elementos do ambiente.

É importante ressaltar a concepção de ambiente nessa teoria, para Bronfenbrenner a mesma deve ir além da sua estruturação física, mas também pelas atividades e relações que nele são estabelecidas. Essa concepção assumida pode ser explicada através dos três pressupostos teóricos, relativos a seus elementos constituintes: a) a natureza e função das atividades molares; b) as estruturas interpessoais como contextos do Desenvolvimento Humano; c) os papéis como contextos do Desenvolvimento Humano.

Estes elementos seriam os blocos construtores de um microssistema definido como "um padrão de atividades, papéis e relações interpessoais experenciados pela pessoa em desen- volvimento num dado ambiente com características físicas e materiais específicas." 12

O indivíduo em desenvolvimento, ao longo de sua existência convive, freqüenta e participa de vários microssistemas, entre eles: a família, o grupo de amigos, a igreja, a escola etc. Cada qual tem suas características específicas onde são realizadas atividades e inúmeras relações são estabelecidas onde ele tanto é influenciado por esses ambientes como os influencia.

Os microssistemas estabelecem relações formando o mesossistema, ou seja, ele "inclui as inter-relações entre dois ou mais ambientes nos quais a pessoa em desenvolvimento participa ativamente (tais como, para uma criança, as relações em casa, na escola e com amigos da vizinhança; para um adulto, as relações na família, no trabalho e na vida social). Um mesossistema é portanto um sistema de microssistemas. ${ }^{13}$

Existem ambientes que não envolvem diretamente a pessoa em desenvolvimento mas nos quais ocorrem eventos que vão influenciar no seu desenvolvimento, estes são denominados de exossistema e "se refere a um ou mais ambientes que não envolvem a pessoa em desenvolvimento como um participante ativo, mas no qual ocorrem eventos que afetam, ou são

${ }^{12}$ Op. cit., p. 18.
${ }^{13}$ Op. cit., p. 21. 
afetados, por aquilo que acontece no ambiente contendo a pessoa em desenvolvimento. ${ }^{14}$

KREBS $^{15}$ evidencia que para essas operações, ocorridas a nível de exossistema, poderem ser identificadas e para que lhes seja atribuída a responsabilidade de qualquer impacto sobre a pessoa em desenvolvimento, é necessário, no mínimo duas condições: 1) que eventos que ocorrem no ambiente externo ao microssistema da pessoa em desenvolvimento tenham conexão com os eventos desse microssistema; 2) que os eventos do microssistema que são conectados com o ambiente externo tenham relação com a pessoa em desenvolvimento. Essas operações podem ocorrer também no sentido contrário, ou seja, da pessoa em desenvolvimento para o exossistema.

Num universo maior estaria o macrossitema que "se refere a consistências, na forma e conteúdo de sistemas de ordem inferior (micro-, mesoe exo-) que existem, ou poderiam existir, no nível da subcultura ou da cultura como um todo, juntamente com qualquer sistema de crença ou ideologia subjacente a essas consistências." "16

Acredita-se que essa teoria é relevante para discutir questões sobre a Educação Física Escolar pois o alu- no, um ser em desenvolvimento, está inserido em vários ambientes e neles realiza e vivencia atividades onde expressa inúmeros comportamentos. Dessa forma, o desenvolvimento jamais ocorre no vácuo; ele está sempre inserido e expresso num comportamento em um determinado contexto ambiental.

\section{Aspectos da educação física es- colar numa abordagem ecológi- ca do desenvolvimento humano:}

\section{O microssistema escola}

A Educação Física pode ser considerada como um componente curricular do sistema educacional, visto que, está presente na escola como uma das disciplinas ou atividade (não cabe aqui a discussão) a serem desenvolvidas e ministradas, tanto no ensino de $1^{\circ}$ como $2^{\circ}$ graus.

A escola será aqui considerada como um microssistema, a presente discussão terá como foco central a aula de Educação Física considerada como uma atividade molar.

Na escola o aluno, pessoa em desenvolvimento, experencia situações de ensino-aprendizagem nas aulas das diversas disciplinas, entre elas a Educação Física.

\footnotetext{
${ }^{14}$ Ibidem.

${ }^{15}$ KREBS, Rui Jornada. Urie Bronfenbrenner e a Ecologia do Desenvolvimento Humano. Santa Maria, RS: Casa Editorial, 1995, p. 37-8.

${ }^{16}$ BRONFENBRENNER, op. cit., p. 21.
} 
Necessário se faz uma reflexão, embora breve, sobre o cotidiano escolar. Acredita-se que para caminhar é preciso estar consciente de onde se está, para então a partir daí perspectivar um novo trilhar e prosseguir. Nesse sentido, é fundamental refletir sobre a realidade, o dia a dia da Educação Física na escola. Como ele está? O que se fez de bom até agora? O que precisa ser mudado?.

Vários estudos (DE MARCO, FREIRE, MOREIRA, WINTERSTEIN...) têm abordado sobre esse cotidiano, embora a leitura se faça em realidades diferentes com enfoques muitas vezes diferentes, constata-se que são ao mesmo tempo muito semelhantes.

DE MARCO diz " Tradicionalmente a educação física sempre buscou, como uma de suas principais metas, desenvolver habilidades e aprimorar capacidades físicas, influenciada talvez por um jargão (exercício, atividade física, treinamento, especialização técnica, esportes, fisiologia do esforço) que induzia pensar em movimento." 17 Ao transportar o que o autor diz para a escola é possível constatar que o objetivo principal da Educação Física, na maioria das vezes, foi (ou é?) desenvolver habilidades visando a performance dos movimentos, predominantemente os esportivos.
Isso é constatado por FINCK ${ }^{18}$ quando analisa a prática do esporte nas aulas de Educação Física, de $5^{\mathrm{a}}$ a $8^{\mathrm{a}}$ série, em algumas escolas públicas do Estado do Paraná.

Como as aulas de Educação Física se caracterizam, predominantemente, nas escolas?

MOREIRA responde dizendo "Apesar de algumas tentativas isoladas, o quadro da Educação Física escolar, no momento, assim se apresenta: sem identidade, acrítica, transmitindo e controlando o ritmo das atividades mecânicas, desenvolvendo conteúdos ao sabor dos modismos, buscando a perfeição do gesto e descompromissada com o indivíduo e com a sociedade." 19

Nesse sentido, é necessário e urgente buscar sentido e significância para a Educação Física na escola, e para isso é fundamental considerar o aluno sob uma outra dimensão, humana, global, dinâmica e contextualizada no todo.

\section{A aula de educação física como atividade molar}

BRONFENBRENNER (1979) diz que as atividades molares devem ser enten-

\footnotetext{
${ }^{17}$ DE MARCO, Ademir. In DE MARCO, op.cit., p. 33.

${ }^{18}$ FINCK, Silvia Christina Madrid. Educação Física e Esporte: uma visão na Escola Pública. Dissertação de Mestrado. Piracicaba, SP: UNIMEP, 1995.

${ }^{19}$ MOREIRA, Wagner Wey. Por uma concepção sistêmica na pedagogia do movimento. In MOREIRA, Wagner Wey (org.). Educação Física \& Esportes: perspectivas para o século XXI. Campinas, SP: Papirus, 1992, p. 204.
} 
didas como diferentes formas de comportamento, o que não significa que qualquer forma de comportamento seja uma atividade molar. Tal distinção é feita acreditando-se que nem todos os comportamentos são, igualmente, significantes ou influentes no desenvolvimento. Para que uma atividade seja considerada como molar, é preciso que tenha uma certa persistência temporal e uma significância para os indivíduos envolvidos no ambiente. A mesma é por ele assim definida "Uma atividade molar é um comportamento continuado que possui um momento (quantidade de movimento, impulso) próprio e é percebido como tendo significado ou intenção pelos participantes do ambiente." 20

Algumas atividades menos significantes e de pequena duração são denominadas de atividades moleculares, estas não influenciam o desenvolvimento do indivíduo, são caracterizadas por um comportamento efêmero, completam e fazem parte de nosso cotidiano.

A definição de atividade molar, portanto, enfatiza tanto alguma persistência temporal quanto certa importância no campo fenomenológico da pessoa em desenvolvimento e de outras pessoas presentes no ambiente. Portanto, para que uma atividade seja considerada como molar é preciso uma certa persistência temporal e uma significância para os indivíduos envolvidos no ambiente. ${ }^{21}$

A aula de Educação Física, numa abordagem ecológica, seria o principal veículo para a influência direta do meio ambiente sobre a pessoa em desenvolvimento, ou seja, o aluno. Dessa forma, para ser considerada como atividade molar é preciso que as atividades realizadas, na mesma, tenham sentido e significância para o aluno $\mathrm{e}$, intencionalidade responsável e compromissada por parte do professor. É importante o educador questionar sobre: $\mathrm{O}$ que ensinar? Por que ensinar? Para quem e como ensinar?. Caso contrário, a aula será apenas uma atividade molecular, de mínima importância para o aluno, apenas completando seu cotidiano escolar, não influenciando no seu desenvolvimento.

Aquilo que o indivíduo realiza, compreendendo o que e por que está fazendo, passa a ter sentido e importância para ele, que dessa forma incorpora o conhecimento e realmente aprende. A respeito da relação que deve existir entre o fazer e o compreender FREIRE Se posiciona dizendo "Não basta fazer, é preciso compreender. [...] Portanto, compreender o que faz é um direito humano. E nós nos empolgamos com a apresentação das habili-

${ }^{20}$ BRONFENBRENNER, op. cit., p. 37.

${ }^{21}$ KREBS. Desenvolvimento Humano: teorias e estudos. Op. cit., p. 105. 
dades motoras de nossos alunos, ignorando, por vezes, que eles não compreendem quase nada daquilo que fazem." 22

Os conteúdos da Educação Física tem todo um simbolismo específico, por exemplo o vocabulário utilizado nas modalidades esportivas como: garrafão, bandeja, drible, saque, bloqueio, rodízio, progressão e outros. $\mathrm{O}$ professor, muitas vezes, usa esses termos sem considerar que para o aluno eles não são tão familiares quanto o são para ele. Para ocorrer a aprendizagem é importante que o aluno não só execute movimentos nas aulas, mas compreenda-os em sua totalidade.

\section{Os papéis}

$\mathrm{Na}$ Teoria Ecológica de Bronfenbrenner os papéis são tidos "como um conjunto de atividades pertinentes a cada determinada posição, que indica não apenas as expectativas da sociedade em relação ao ocupante da posição, mas também as expectativas que o ocupante da posição tem no que diz respeito ao que os demais membros da sociedade esperam dele próprio."23

Em qualquer ambiente o indivíduo ocupa um determinado papel, isto é à ela cabe desempenhar funções que são específicas do mesmo, a sociedade espera dele determinados comporta- mentos que condizem com o papel que ele ocupa, sendo que o indivíduo também tem expectativas em relação ao seu próprio desempenho.

No ambiente da escola as pessoas executam atividades que correspondem à diferentes papéis que as mesmas representam, entre eles: diretor, professor, inspetor, aluno, colega, amigo. Especificamente, nas aulas de Educação Física, ao participar das diversas atividades, o aluno ocupa papéis como: companheiro, adversário, jogador, juiz, entre outros.

Para Bronfenbrenner o desenvolvimento do indivíduo se dará de forma mais efetiva quanto maior o número de papéis que ele ocupar nos diferentes microssistemas do qual ele participa, assim como, maior for o número de relações que estabelecer com pessoas que ocupam diversos papéis.

Nesse sentido, é importante a diversidade e pluralidade das atividades nas aulas de Educação Física, pois, dessa forma o aluno terá oportunidade de vivenciar diferentes situações e papéis, sendo seu desenvolvimento mais completo.

\section{As estruturas interpessoias}

$\mathrm{Na}$ escola são estabelecidas inúmeras relações, entre elas: aluno/alu-

\footnotetext{
${ }^{22}$ FREIRE, João Batista. In op. cit., p. 44.

${ }^{23}$ KREBS. Desenvolvimento Humano: teorias e estudos. Op. cit., p. 109.
} 
no, professor/professor, professor/aluno. No processo ensino-aprendizagem essa última é determinante na consecução do mesmo, podendo se dar de forma positiva ou negativa.

Numa perspectiva ecológica a presença de uma relação em ambas as direções estabelece a condição mínima e definidora para a existência de uma díade ou díada. ${ }^{24}$

Assim, uma díade é formada sempre que duas pessoas prestam atenção nas atividades uma da outra ou delas participam. A díade é importante para o Desenvolvimento Humano em dois aspectos: $1^{\circ}$ ) ela por si só constitui um contexto crítico para o desenvolvimento; $2^{\circ}$ ) Ela serve como bloco construtor básico do microssistema, possibilitando a formação de estruturas interpessoais maiores tríades, tétrades e assim por diante.

Certas propriedades são características de todas as díades a reciprocidade, o equilíbrio de poder e a relação afetiva. A reciprocidade está relacionada à maneira como os participantes da díade interagem entre si, essa interação pode gerar uma força motivacional própria, capaz de levar os indivíduos a uma maior perseverança no engajamento progressivo em padrões de interações mais complexas. Embora, a idéia de reciprocidade sugira uma igualdade de poder, o ideal é existir a alternância do mes- mo, isto é que o domínio não permaneça sempre com a mesma pessoa, havendo então um equilíbrio. Uma situação ideal de aprendizagem seria àquela onde seriam dadas um maior número de oportunidades para o aluno exercitar o controle sobre a situação. Numa relação de díade, a medida que os indivíduos se envolvem tendem a desenvolver sentimentos mais pronunciados em relação uns aos outros, os quais variam quanto à qualidade, podendo ser de características positivas, negativas, ambivalentes ou assimétricas. Portanto, uma relação afetiva pode envolver tanto sentimentos tidos como positivos como pode acontecer o contrário, isto é, a afetividade não diz respeito necessariamente só a "bons" sentimentos, mas também a "maus". Em termos de seu potencial para fomentar o crescimento psicológico a díade pode assumir três formas funcionais diferentes: observacional, de atividade conjunta e primária.

Uma díade observacional ocorre quando um membro está prestando uma cuidadosa e continuada atenção à atividade do outro, que por sua vez reconhece o interesse sendo demonstrado. No entanto, essa díade só se efetivará a partir do momento em que a pessoa, foco de atenção, emitir algum tipo de resposta ao seu observador. É possível dizer que uma aula de

\footnotetext{
${ }^{24}$ Bronfenbrenner (1979) utiliza o termo díade. Krebs (1995) utiliza o termo díada. Neste trabalho optou-se pelo uso do primeiro termo.
} 
Educação Física com características mais tradicionais, onde o professor é o detentor do saber (modelo) e o aluno apenas observa e tenta imitá-lo, a relação estabelecida se aproximaria de uma díade observacional.

Uma díade de atividade conjunta é aquela em que os dois participantes se percebem como fazendo alguma coisa juntos. Isso não significa que eles estão fazendo a mesma coisa. Pelo contrário, as atividades que cada um realiza tendem a ser um pouco diferentes, mas complementares, parte de um padrão integrado. Esse tipo de díade apresenta condições especialmente favoráveis não só para a aprendizagem no curso da atividade comum, mas também para uma crescente motivação visando buscar e complementar a atividade quando os participantes não estiverem mais juntos. $\mathrm{O}$ poder desenvolvimental de uma díade de atividade conjunta se deriva do fato de ela intensificar e, portanto, apresentar em grau mais acentuado os sentimentos que caracterizam a relação estabelecida.

Uma díade primária é aquela que continua existir fenomenologicamente para ambos os participantes mesmo quando eles não estão juntos. Os dois membros aparecem nos pensamentos de cada um, são objeto de fortes sentimentos emocionais e continuam a influenciar o comportamento um do outro mesmo quando separados. Estas díades exercem uma poderosa influência na motivação para a aprendizagem e na orientação do curso do desenvolvimento tanto na presença quanto na ausência da outra pessoa.

Cabe ressaltar que estas estruturas combinadas têm um impacto desenvolvimental mais poderoso do que as díades limitadas a um único tipo.

\section{Considerações finais}

A Teoria Ecológica do Desenvolvimento Humano de Urie Bronfenbrenner é bastante complexa, ao utilizá-la como referencial para as questões abordadas e discutidas, neste trabalho, referentes a Educação Física Escolar, não foi intenção tornála simples e reducionista, pelo contrário, foi justamente por reconhecer sua amplitude e complexidade quando trata como foco de estudo a acomodação progressiva entre organismos humanos em desenvolvimento e seus ambientes imediatos.

Considerando o aluno, um ser em desenvolvimento, inserido em vários ambientes (microssistemas) entre eles a escola, e a aula de Educação Física uma atividade molar, é possível dizer que o conhecimento a ser tratado, assim como, a significância que terá para o aluno e as relações interpessoais estabelecidas, dependem em grande parte do trabalho competente e responsável desempenhado pelo professor, portanto, ele representa um papel mediador fundamental no processo ensino-aprendizagem. 


\section{REFERÊNCIAS}

\section{BIBLIOGRÁFICAS}

1 BRONFENBRENNER, Urie. A

Ecologia do Desenvolvimento

Humano: experimentos naturais e planejados. Trad. Maria Adriana Veríssimo Veronese. Porto Alegre: Artes Médicas, 1996.

2 DE MARCO, Ademir. (org.). Pensando a Educação Motora. Campinas: Papirus, 1995.

3 KREBS, Rui Jornada et al. Desenvolvimento Humano: uma área emergente da ciência do movimento humano. Santa Cruz do Sul, [s.n], 1996.

4 KREBS, Rui Jornada. Desenvolvimento Humano: teorias e estudos. Santa Maria: Casa Editorial, 1995.

5 . Urie Bronfenbrenner e a Ecologia do Desenvolvimento

Humano. Santa Maria, RS: Casa Editorial, 1995.

6 MOREIRA, Wagner Wey. (org.). Educação Física \& Esportes: perspectivas para o século XXI. Campinas: Papirus, 1992. 